\title{
Constraints, Stakeholders, and Framing Goals in Energy Master Planning Between Neighborhood and District
}

\author{
Matthias Haase and Daniela Baer
}

\begin{abstract}
This paper analyzes and contrasts the constraints, stakeholders, and framing goals that must be considered when Energy Master Planning (EMP) is conducted for communities in seven countries. The analysis is based on findings from seven countries participating in the International Energy Agency's "Energy in Buildings and Communities Program Annex 73". The analysis covers design constraints such as emissions, sustainability criteria, and resilience goals, regulations and directives, regional and local limitations, such as available energy types, local conditions, and various levels of stakeholders, as well as community objectives. An analysis of the various constraints on different planning levels was done, and the key stakeholders were identified. They can be characterized by different governance structures and thereby stakeholder constellations. Mapping of the stakeholders involved provides insights in further constraints resulting into issues within the EMP that will need to be addressed for multi-owner, multi-stakeholder neighborhoods and districts. With a closer look at a case study in Elverum, Norway, the paper identifies constraints related to stakeholders involved and their impact on applying EMP.
\end{abstract}

Keywords Stakeholder analysis $\cdot$ Energy master planning $\cdot$ Neighborhood level

\section{Introduction}

Climate change challenges regulators to put in place more ambitious building and community energy-related requirements to fulfill the ambitions Sustainable Development Goals of the UN.

In the EU, reaching the climate gas-reduction goals of the Paris Agreement challenges stakeholders on all geographical and organizational levels from nations,

M. Haase $(\bowtie) \cdot D$. Baer

ZHAW Zurich University of Applied Sciences, Wädenswil, Switzerland

e-mail: matthias.haase@zhaw.ch

D. Baer

SINTEF Community, Trondheim, Norway

(C) The Author(s) 2021

A. Bisello et al. (eds.), Smart and Sustainable Planning for Cities and Regions, Green Energy and Technology, https://doi.org/10.1007/978-3-030-57764-3_1 
regions, cities, and communities. Following bottom-up approaches for energy planning on the neighborhood level is a promising attempt to reduce energy demand, increase efficiency, and lower the carbon footprint in a multi-stakeholder approach. This is important for the future task to decarbonize our cities, which will have to focus on neighborhood and district level (Jank 2017). The concept of Energy Master Planning (EMP) can help to initiate a better planning and implementation process to fulfill these goals through providing a roadmap for energy planning. The application of principles of a holistic approach to neighborhoods and districts often termed community energy planning in the literature (EED 2012; Jank 2017; StrømannAndersen 2012; Fox 2016; Zhivov et al. 2014; Robinson et al. 2009) and the concept of Energy Master Planning (EMP) can help to initiate a better planning and implementation process to fulfill these goals by providing a roadmap for energy efficiency in the district as a basis for energy planning that points to the future. Haase and Lohse (2019) tried to define EMP and explained the various steps involved in the process: (1) energy efficiency and (2) comprehensive energy planning.

(1) When it comes to energy efficiency, in the context of the 2012 EU directive (EED 2012), several important measures have been adopted throughout the EU to improve energy efficiency. These include national long-term renovation strategies for the building stock in each EU country, mandatory energy-efficiency certificates accompanying the sale and rental of buildings, the preparation of national energy-efficiency action plans (NEEAPs) every three years, minimum energy-efficiency standards, and labeling for a variety of products, as well as obligation schemes for energy companies (to achieve yearly energy savings of $1.5 \%$ of annual sales to final consumers). However, Member States have yet to fully implement the directive and additional support in building capacity and know-how is needed (EPBD 2018).

(2) Significant additional energy savings, reduced emissions, and increased energy security can be realized by considering holistic solutions for the heating, cooling, and power needs of communities, on the neighborhood and district scales, comprising collections of buildings. As a result, a considerable amount of literature has become available including both guidance and assessment tools aimed at EMP at the neighborhood and district level, e.g., campuses (DOE 2013; Huang et al. 2015; EnergyPlan 2019; CASBEE 2019; BREEAM 2019; LEED 2019). But the existing guidance and tools do not seem to be fully solving the challenges. The energy planning consists of determining the optimal mix of energy sources to satisfy a given energy demand. The major difficulties of this issue lie in its multi-dimensional and scale aspects (temporal and geographical), but also in the necessity to consider the quantitative (economic, technical), but also qualitative (environmental impact, social criterion), criteria.

In addition, Schiefelbein et al. (2017) concluded in their investigation of case studies and energy guidelines for energy-efficient communities that "the primary challenges result from inefficient organizational processes and unsupportive framework for implementation". 
To provide the necessary methods and instruments to the stakeholders involved, it is essential to identify and frame the constraints that bound the options towards an optimized energy master planning solution (Sharp et al. 2020). Existing literature on EMP guidance indicates that identifying and establishing project goals is a critical first step (Jank 2017).

Far less common in EMP guidance and related literature is information on the identification of constraints that limit energy technology options and how stakeholders influence the decision-making process. Literature in this area mentions options analysis or prioritization, or optimization analysis (EED 2012; Fox 2016; Robinson et al. 2009; Zhivov et al. 2017), but few mention constraint identifications related to energy technologies as Sharp et al. (2020) pointed out when comparing energy technology constraints in EMP in the seven countries. Although the work of Sharp et al. (2020) contributes by widening the definition of constraints into EMP, it is limited in its scope by focusing on single-ownership neighborhoods like campuses or military garrisons.

Not much work is done on constraints, stakeholders, and boundary conditions in EMP for multi-owner, multi-stakeholder neighborhoods. But many cities and regions are characterized by diverse ownerships and a multitude of stakeholder groups involved, which results in more complex framing goals that can lead to further constraints in EMP.

\section{Objectives}

As more and more countries push to improve the efficiency, environmental impact, and the resilience of buildings and neighborhoods, the need for front-end comprehensive EMP on a neighborhood level is critically important. A successful EMP is highly dependent on a thorough understanding of framing goals and constraints, both local and regional, and their associated limitations that will dictate the optimum master planning design. This paper addresses the gap by developing a broader framework of EMP by incorporating framing goals and constraints for energy technologies and stakeholders' engagement within a multi-stakeholder (eco)system on a neighborhood level.

\section{Method}

Our research approach is twofold: in the first step, we analyze framing goals and constraints for energy technologies on a global level by comparing seven countries, as part of a larger effort to analyze existing EMP practice in an international team with partners from Austria, Australia, Denmark, Finland, Germany, Norway, and the USA. A constraint analysis based on ongoing research in the participating countries 
for single owner neighborhoods (military bases and campuses) was used in this step (Sharp et al. 2020).

In the second step, we chose an in-depth analysis of stakeholders involved in EMP on a neighborhood level. We have chosen a case area in Norway because the case is the furthest developed when it comes to the availability and application of new energy technologies, as well as access to stakeholders (availability of interview partners and data was given).

\subsection{Analysis of Design Constraints}

The constraint analysis was divided into two steps. The first analysis of framing goals in seven countries (Austria, Australia, Denmark, Finland, Germany, Norway, and the USA) covers design constraints such as emissions, sustainability criteria and resilience goals, and regulations and directives and regional and local limitations, such as available energy types, local conditions and different levels of stakeholders, as well as community objectives. It then illustrates how a comprehensive consideration of these can be used to guide the planner toward design options that will lead to an optimum solution for a master plan. The second analysis was based on the local constraints and site-specific goals in the case study of Ydalir in Norway. With this analysis, the key stakeholders were identified, characterized by different governance structures and thereby stakeholder constellations.

\subsection{Mapping of Key Stakeholders}

The case of Ydalir in the city of Elverum was chosen as a case study as one of nine pilot projects within the Research Centre on Zero Emission Neighborhoods which has implemented various phases of EMP. Nine stakeholders involved from various sectors were interviewed and transcripts of the interviews were analyzed applying qualitative content analysis (Mayring 2000).

This mapping of the stakeholders involved gives insights into other constraints resulting in issues within the EMP that will need to be addressed for multi-owner, multi-stakeholder neighborhoods.

\section{Results}

Local stakeholders are interested in natural locational constraints, but also are planners who relate their design on locational constraints such as climate data on wind access, solar radiation, air-temperature distribution and time series, and water (and wind) temperatures. 
The distribution system and storage constraints are mostly important to local maintenance staff and facility managers, but larger thermal storages equipment could be visible and important for inhabitants as well. Also, the level of noise of the distribution system could be of interest to inhabitants and users in the neighborhood.

When it comes to the building and facility, there are planners and architects involved. The end users or inhabitants play a limited role because they are often unknown and therefore categorized (according to building typology and use of the facility). Here, building codes have the role of defining the minimum requirements that would ensure comfortable use of the building. Involvement of planners and architects is normal, even more so in the next set of constraints that in particular is concerned with the indoor environment. Again, minimum requirements are established through building codes and standards. The building owner can decide on the level of indoor comfort, typically choosing between different levels/classifications (low, medium, high).

When it comes to the equipment in buildings and district systems, the technical functionality is defined in building codes and related standards. Planners and architects have the expertise to define them. However, some technologies can be chosen by the building owner or investor, e.g., if the building shall have a certain heating technology or specific façade technology.

There are different levels for applying EMP within an urban context: starting from the city level, followed by the neighborhood and then the group of buildings with their building regulations. The stakeholders involved can be framed into different categories as illustrated in Fig. 1.

Ideally, the potential reduction goals should be discussed on different levels with the relevant stakeholders in various constellations. A stakeholder forum would encourage a top-down approach, however, in some cases, a bottom-up approach
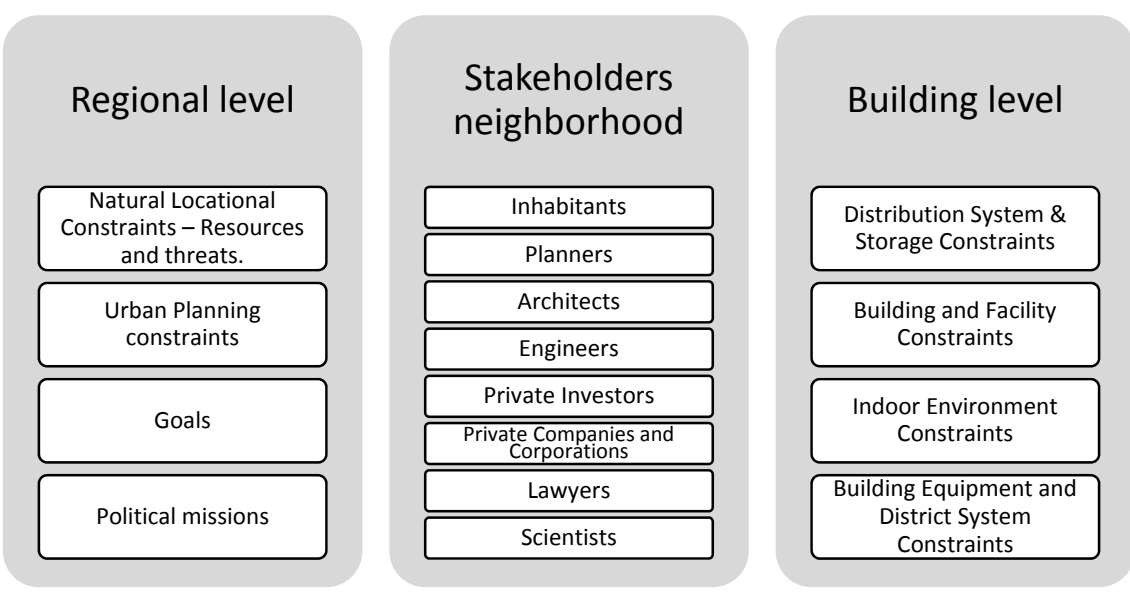

Fig. 1 Stakeholders involved in EMP at neighborhood levels and constraints and framing goals on the regional and building levels 


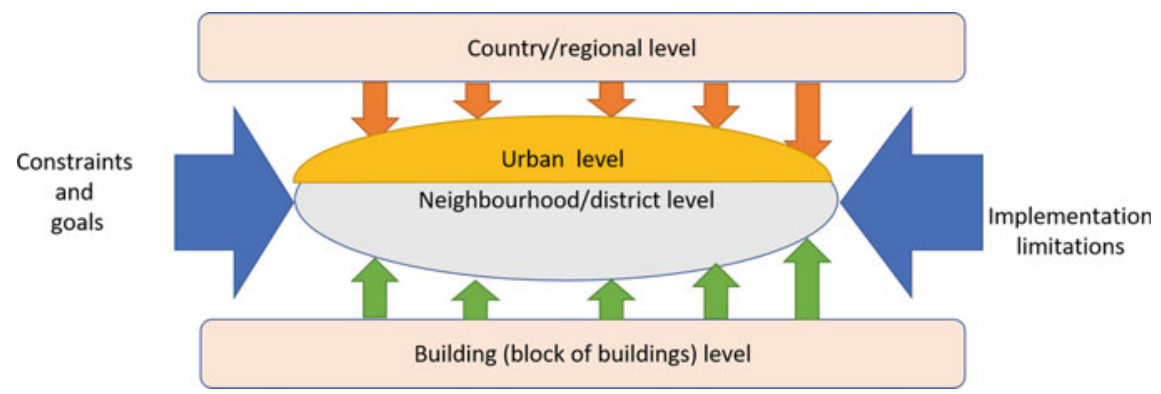

Fig. 2 Constraints in EMP on a neighborhood level

seems more promising. There is the intrinsic problem that different stakeholder perspectives may result in an unclear nature of the problem since stakeholders at different levels view the problem differently. Architects and planners must rethink buildings and spaces; public authorities need to adapt organization and procedures; lawyers need to adapt legal and policy adaptation, etc. This can cause a lack of a unique problem statement and the choice of inadequate solutions for emission reduction.

Figure 2 illustrates the model by visualizing the boundaries in EMP by diagramming the top-down and bottom-up approaches for EMP on a neighborhood level. There are constraints coming from the building level, as well as from the regional level that will limit the technical possible solutions for a site-specific EMP. Various valid objectives possibly conflicting on short-to-medium terms require prioritizing (carbon-free cities; cheap affordable energy for all; regional energy self-sufficiency; job promoting energy system; fully renewable energy sources; etc.). This problem is intensified by the dynamic nature of energy planning parameters (energy price fluctuation; evolving new technologies; population growth; high urbanization rates; changing political actors and agendas etc.).

The quality of physical data is often not available, hindered by privacy and/or measurability issues. This aspect is enhanced by a vast set of technology options, uncertainties on effectiveness, and constantly evolving new solutions at different technological readiness levels.

While locational threats usually do not influence technology selections, locational resource limits, as well as the limits of existing distribution and energy storage systems, can profoundly affect technology selection.

Ambiguity in purpose leads to a lack of clarity about successful outcomes. This may lead to conflicting objectives. On the other hand, ambiguity in values prevents the clear assessment of outcomes. Different stakeholders will value sustainability criteria differently depending on their objective (societal benefits of clean energy opposed to the need for low investment costs, the "landlord- tenant" dilemma; topdown planning or bottom-up collaborative planning; etc.). Therefore, it is important that key performance indicators are introduced and that their weighted values are agreed upon at the beginning of the process. 
Identified framing constraints should be evaluated as either a hard or soft constraint. If not, constraints that can be overcome may be missed and promising technologies stripped out of a final EMP solution.

On the political level, we find often unclear policy responsibilities and ambiguous values to address climate change, as well as disagreement on societal effectiveness of climate change policy. This is enhanced on the administrative level with ill-defined responsibilities, budgets and implementation procedures, no established standardized way on the definition and the monitoring and reporting of key performance indicators. On top of this, governments need to reach sustainability targets and safeguard public interest, while energy providers need to make profits and individuals need to reduce expenses.

\section{Discussion of a Case Study in Norway}

So far, three phases of EMP have been implemented within the Ydalir case-a new neighborhood development within the city of Elverum: goalsetting, assessment and development options and implementation. While two buildings are already completed and in use, the development of a comprehensive plan is still under development (Baer and Haase 2020). We present the following case study under the following three categories: ambitions, commitment to the problem and timeline.

\section{Ambitions}

The ambition for Ydalir is to become zero emission neighborhood (ZEN), the amount of emissions through materials and energy used within the construction and operation phase of the neighborhood shall be offset by locally produced energy (Elverum Tomteselskap 2017).

With regard to energy, these general measures are identified within the master plan to achieve the ambition:

- Buildings built after passive house standard or even better, and a high use of wood or other materials with low greenhouse-gas emissions as a building material,

- District heating based on bioenergy for residential buildings,

- Local electricity generation based on solar cells and bioenergy-based power/heat production.

Within the Assessment and Development Options phase of EMP, three studies were undertaken in 2018 and 2019 to analyze future energy and emission performances. Lund et al. (2019) applied a Lifecycle Assessment analysis (LCA) model for neighborhood development based on a modular structure, integrating buildings, mobility, infrastructure, networks, and on-site energy. The study reveals that, regardless of which scenario is considered, the Ydalir project does not achieve the ambitious goal of becoming a zero-emission neighborhood, using the existing planning status as the basis for consideration. 
There are several general factors particularly influencing the Ydalir development with regard to attaining high ambitions in cutting down energy and emissions. Through qualitative interviews with the stakeholders involved, we have identified two main factors: commitment to the project and the timeline, that do influence the stakeholders involved and the implementation of EMP (Baer and Haase 2020).

\section{Commitment to the Project}

The analysis has shown that commitment to the project depends on the individual stakeholder's vision and agenda. The collaborative development process of the master plan was pointed out by the interviewees as an important step for knowledge and trust development besides the establishment of a common understanding and vision, thereby strengthening the commitment to the ambitious project goal. The local land-development agency ETS received co-funding for the master plan development through Enova, the Norwegian environmental funding agency. Housing developers are indicated as crucial in this phase of development because they have to commit to the general vision of Ydalir by developing an energy system and buildings with climate ambitions that go beyond existing regulations. In its first version, the master plan of Ydalir contained no parking lots for buildings, but the establishment of a car park. These ambitions were already lowered and parking spaces allowed because housing developers feared a lack of interest from buyers. The fear of higher development costs due to higher building standards is also expressed by housing developers and could influence future commitments.

\section{Timeline}

The timeline is always a factor influencing project development, but it is especially important because planning of the energy system and the management of the system, including reducing load on the system, depends on the realization of a minimum quantity of buildings and infrastructure within a limited timeframe. In this phase of development, windows of opportunities are open regarding developing a holistic energy system based on minimized loads. It is much more difficult to realize economies of scale for energy solutions if they are added stepwise to the neighborhood system. The time of realization of community services such as the car park is crucial for housing developers with regard to developing their own plots. Future buyers may not be interested to buy houses without their own parking lots as long as the planned shared car park at a central position is not in place.

\section{Conclusions}

This paper addresses the gap by developing a broader framework of EMP by incorporating framing goals and constraints for energy technologies and stakeholder's engagement within a multi-stakeholder (eco)system on neighborhood level.

The energy master planning on a neighborhood level is confronted with constraints from higher and lower levels. A city consists of several districts or neighborhoods, 
which must have a consistent energy plan within the municipal EMP. This strategic level from urban planning, as well as natural constraints, are limiting options from the top, while a number of imposed constraints limit technology selection from the bottom. This understanding should be taken into consideration when an EMP is conducted. The stakeholders involved play a crucial role when it comes to EMP and its implementation. The main barriers identified have a strong impact on EMP and are all influential by the stakeholders involved. However, due to the complexity of urban planning and energy master planning, there remain some issues. These issues point to a wicked problem that needs to be solved. The main issue is linked to how to best involve different stakeholders in the EMP process. Which tools are needed to facilitate the stakeholder involvements? How does one communicate and visualize analysis results in the decision-making group?

In the study on the neighborhood of Ydalir, we identified the stakeholders involved, as well as stakeholder constraints with regard to EMP and its implementation. The type of stakeholders involved, how they communicate, and how they are involved in the process play a crucial role. The main barriers identified have a strong impact on EMP and are mainly influenced by the involved stakeholders themselves. The Ydalir case has shown that a collaborative master plan development can help to strengthen the commitment to the project and lower uncertainty in an early phase of development. The realization of this collaborative process was enabled through the initiative, and thereby commitment, of ETS. The external funding was crucial here, as financial resources for broad stakeholder engagement are often limited.

To maintain consistent quality in the EMP process, it is recommended that the identification of framing constraints and their limits, and perhaps their evaluation, be standardized (perhaps starting in checklist form). If identifying constraints and applying their limits were standardized, the results here could perhaps help to establish a baseline that can be used by others, built upon experiences, and improved to establish a standardized process. For the concept of EMP applied on the neighborhood level with multiple stakeholders involved, we learned through the Ydalir case that there is a need to incorporate aspects of stakeholder management and engagement, process management, and tools for the identification of the appropriate neighborhood design. As there are today, no tools or indicators available, as well as a lack of interest from the academic side, to identify appropriate neighborhood sizes, we recommend elaborating and identifying appropriate neighborhoods within a multi-stakeholder approach by screening the whole city and/or region. In this selection process, factors, e.g., constraints regarding available energy sources, possible stakeholders involved and their interests, and location within the greater urban and regional infrastructure system, have to be considered. We recommend conducting a SWOT-analysis to assess development opportunities with regard to strengths, weaknesses, opportunities, and threats for neighborhood development, in general, and specifically in realizing ambitious energy and emission goals.

Acknowledgements The authors gratefully acknowledge the support from the Research Council of Norway and its partners through the Research Centre on Zero Emission Neighborhoods in Smart 
Cities (FME ZEN). Additionally, we acknowledge the support of Enova for discussions within the IEA EBC Annex 73 participation.

\section{References}

Baer D, Haase M (2020) Energy master planning on neighbourhood level: learnings on stakeholders and constraints from the Norwegian case of Ydalir, Accepted for publication in proceedings world sustainable built environment conference, Gothenburg, Sweden

BREEAM (2019) bre environmental assessment method. https://www.breeam.com/. Accessed 13 Aug 2019

CASBEE (2019) Comprehensive assessment system for built environment efficiency. https://www. ibec.or.jp/CASBEE/english/. Accessed 19 Aug 2019

EED-Directive 2012/27/EU of the European parliament and of the council of 25 October 2012 on energy efficiency. Energy Efficiency Directive. https://ec.europa.eu/energy/en/topics/energyefficiency/targets-directive-and-rules/energy-efficiency-directive. Accessed 04 Dec 2019

Elverum Tomteselskap (2017) Ydalir Masterplan Del 1. https://www.ydalirbydel.no/wp-content/ uploads/2017/12/Ydalir-Masterplan.pdf. Accessed 02 Feb 2019

EnergyPlan. Energy systems simulation tool. https://www.energyplan.eu/. Accessed 13 Aug 2019

EPBD (2018) Directive (EU) 2018/844 of the European parliament and of the council of 30 May 2018 amending directive 2010/31/EU on the energy performance of buildings. https://eur-lex.eur opa.eu/legal-content/EN/TXT/?uri=uriserv\%3AOJ.L_.2018.156.01.0075.01.ENG. Accessed 13 Aug 2019

Fox K (2016) Energy master planning perspectives and best practices, presentation to the federal utility partnership working group, May 2016. Cincinnati, OH

Haase M, Lohse R (2020) Process of energy master planning of resilient communities for comfort and energy solutions in districts. In: IOP conference series: earth and environmental science, vol 352, number 1, IOP Publishing Ltd. https://iopscience.iop.org/article/https://doi.org/10.1088/ 1755-1315/352/1/012019. Accessed 09 Feb 2020

Huang Z, Yu H, Peng Z, Zhao M (2015) Methods and tools for community energy planning: a review. Renew Sustain Energy Rev 42(C):1335-1348 (Elsevier)

Jank R (2017) Annex 51: case studies and guidelines for energy efficient communities. Energy Build 154:529-537

LEED. Leadership in energy and environmental design. https://leed.usgbc.org/leed.html. Accessed 19 Nov 2019

Lund KM, Lausselet C, Brattebø H (2019) LCA of the zero emission neighbourhood Ydalir. In: IOP conference series: earth and environmental science, vol 352, issue 1

Mayring P (2000) Qualitative content analysis. Forum: Qual Social Res 1(2)

Robinson D et al (2009) CITYSIM: comprehensive micro-simulation of resource flows for sustainable urban planning. In: Eleventh International IBPSA Conference on Building Simulation 2009, Glasgow, Scotland, July 2009

Schiefelbein J et al (2017) Implementation of energy strategies in communities-results within the context of IEA annex 63. In: 30th international conference on efficiency, cost, optimization, simulation and environmental impact of energy systems, ECOS 2017-San Diego, CA, US

Sharp T, Haase M, Zhivov A, Rismanchi B, Lohse R, Rose J, Nord N (2020) Energy master planning: identifying framing constraints that scope your technology options. American Society of Heating, Refrigerating and Air-Conditioning Engineers Inc., Atlanta, ASHRAE transactions

Strømann-Andersen JB (2012) Integrated energy design in master planning. Kgs. Lyngby: DTU. Byg Rapport, No. R-254

Zhivov A et al (2014) Energy master planning towards net-zero energy communities/campuses. In: ASHRAE transactions. ASHRAE Engineers, Inc., Atlanta 
Zhivov A et al (2017) Technologies integration to achieve resilient, low-energy military installations. Proposal No. EW18-5281 to the U.S. Department of Defense Environmental Security Technology Certification Program

Open Access This chapter is licensed under the terms of the Creative Commons Attribution 4.0 International License (http://creativecommons.org/licenses/by/4.0/), which permits use, sharing, adaptation, distribution, and reproduction in any medium or format, as long as you give appropriate credit to the original author(s) and the source, provide a link to the Creative Commons license, and indicate if changes were made.

The images or other third party material in this chapter are included in the chapter's Creative Commons license, unless indicated otherwise in a credit line to the material. If material is not included in the chapter's Creative Commons license and your intended use is not permitted by statutory regulation or exceeds the permitted use, you will need to obtain permission directly from the copyright holder.

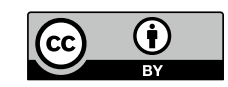

